\title{
A Mensuração do Produto Interno Bruto do Complexo Agroindustrial do
}

\section{Agronegócio de Goiás}

\author{
The Measurement of the Gross Domestic Product of the Agribusiness Agro-Industrial Complex of
}

Goiás

Medida del Producto Interno Bruto del Complejo Agrícola de Agronegocios de Goiás

Recebido: 05/04/2021 | Revisado: 12/04/2021 | Aceito: 15/04/2021 | Publicado: 29/04/2021

Guilherme Cunha Malafaia

ORCID: https://orcid.org/0000-0001-8565-1053

Empresa Brasileira de Pesquisa Agropecuária, Brasil

E-mail: guilherme.malafaia@embrapa.br

Daniel Massen Frainer

ORCID: https://orcid.org/0000-0003-0813-214X

Universidade Estadual do Mato Grosso do Sul, Brasil

E-mail: danielfrainer@gmail.com

Yasmin Gomes Casagranda

ORCID: https://orcid.org/0000-0001-9363-9716

Universidade Federal do Mato Grosso do Sul, Brasil

E-mail: yasmin.casagranda@ufms.br

Denise Barros de Azevedo

ORCID: https://orcid.org/0000-0003-0253-8616 Universidade Federal do Mato Grosso do Sul, Brasil

E-mail: deniseazevedo1972@gmail.com

\begin{abstract}
Resumo
O agronegócio é setor primordial para a economia do Brasil, sendo o estado de Goiás um dos seus protagonistas. Na mensuração da participação relativa, a agropecuária tem maior expressividade com participação de 37,48\% na composição do PIB do complexo agroindustrial do agronegócio de Goiás. Essa atuação ativa representa os setores urbanos e seu vínculo com os setores da economia do estado. Desagregado este dado, a pecuária apresenta 38,67\% de participação no total, enquanto a agricultura apresenta $61,33 \%$. Do PIB total estadual o valor relativo de $27,60 \%$ é a participação PIB do agronegócio. O uso da matriz de insumo-produto com a compilação dos valores adicionados a preços do consumidor tornou possível a análise detalhada também de insumos, agroindústria e agroserviços. Este último teve participação de $27,74 \%$ do PIB calculado para o agronegócio do estado. A dinâmica encontrada mostra a o grau de dependência da economia estadual e nacional de cada um dos agregados econômicos analisados.
\end{abstract}

Palavras-chave: Insumo-produto; PIB; Agronegócio.

\begin{abstract}
Agribusiness is a prime sector for the economy of Brazil, with the state of Goiás as one of its protagonists. In measuring the participation related to agriculture and livestock, it is more expressive with a $37.48 \%$ share in the composition of the GDP agribusiness agro-industrial complex of Goiás. This active performance represents the urban sectors and their link with the sectors of the state economy. This data disaggregated, livestock has a $38.67 \%$ share in the total, while agriculture has $61.33 \%$. Of the total state GDP, the relative value of $27.60 \%$ is the GDP share of agribusiness. The use of the input-output matrix with the compilation of the added values at consumer prices made it possible to also analyze in detail the inputs, agribusiness and agri-services. The latter accounted for $27.74 \%$ of the state's agribusiness GDP calculated. The dynamics found shows the degree of dependence on the state and national economy for each of the economic aggregates analyzed.
\end{abstract}

Keywords: Input output; GDP; Agribusiness.

\section{Resumen}

La agroindustria es un sector primordial para la economía de Brasil, con el estado de Goiás como uno de sus protagonistas. En la medición de la participación relativa, la agricultura es más expresiva con una participación del 37,48\% en la composición del PIB del complejo agroindustrial de la agroindustria de Goiás, este desempeño activo representa a los sectores urbanos y su vinculación con los sectores de la economía estatal. Desagregando esta cifra, la ganadería tiene una participación del 38,67\% en el total, mientras que la agricultura tiene el 61,33\%. Del PIB total del estado, el valor relativo del $27,60 \%$ es la participación del PIB de la agroindustria. El uso de la matriz insumoproducto con la compilación de los valores agregados a precios de consumo permitió analizar también en detalle los 
insumos, agronegocios y agroservicios. Este último representó el 27,74\% del PIB calculado para la agroindustria del estado. La dinámica encontrada muestra el grado de dependencia de la economía estatal y nacional para cada uno de los agregados económicos analizados.

Palabras clave: Insumo-producto; PIB; Agroindustria.

\section{Introdução}

Como setor essencial para a economia brasileira o agronegócio é considerado um vetor de crescimento do país. Na história recente o setor tem absorvido um terço dos trabalhadores e o seu desempenho é refletido nos resultados internos e externo, como é o caso da balança comercial.

Com desempenho superior à média da economia brasileira, em 2019 o PIB (renda) do agronegócio teve um crescimento de 3,81\% (CNA, 2019). O aumento se deu também na sua representatividade e participação na economia brasileira, que em 2018 era de $21.1 \%$ e em 2019 passou a ser de $21.4 \%$. Entre agricultura e pecuária, a primeira teve um recuo de $3,46 \%$, enquanto a segunda teve um crescimento expressivo de $23.71 \%$ (CEPEA, 2019).

O desempenho notado no âmbito rural contribui diretamente para o desenvolvimento econômico do país. Esses resultados estão atrelados a estudos voltados para ciência, tecnologia e inovação (CI\&T) que leva também a melhores condições para o relacionamento com as políticas públicas e com os produtores nas diversas cadeias produtivas existentes (EMBRAPA, 2018).

Entre os meses de dezembro de 2016 e 2018 mostra que a exportações do agronegócio brasileiro teve resultado 37,08\% superior (AGROSTAT, 2019). Tal expressividade dos números pode ser considerada pela produtividade do setor, bem como pela geração de emprego e renda que a atividade proporciona.

O estado de Goiás, segundo maior produtor de gado de corte do Brasil, apresentou em 2017 um aumento de 34,4\% na sua produção de grãos, com 22,81 milhões de toneladas. Diante do cenário nacional no mesmo ano teve consolidada a primeira posição no país em produção de tomate e de sorgo (em grãos) (IMB, 2017b). No ano de 2016 o estado teve queda no seu PIB de $3,5 \%$, que poderia ser maior não fosse o aumento de 0,4\% na agropecuária, que se estendeu em 2017 para um aumento de $19,2 \%$ (IMB, 2016, 2017a).

A diversificação do setor mostra que há uma tendência de maior crescimento com destaques para a participação do agronegócio com 70,6\% das exportações do estado. Dentre os destaques, o aumento de 60,4\% da participação da carne bovina e 72,7\% do algodão em 2019 (SEAPA, 2019).

A base para entendimento teórico é dada pela concepção de um agrupamento de setores da economia. Este foi o conceito que levou à concepção da teoria de Insumo-Produto, que se baseou na dificuldade de construção de uma tabela com a descrição de todas as transações que ocorrem entre unidades econômicas independentes e a economia nacional (Leontief, 1936).

Para a análise insumo-produto é apresentada uma perspectiva que pode ser aplicada de maneira local, regional ou nacional. Há a concepção de uma relação de igualdade entre bens vendidos e comprados dentro da economia em análise. Sendo, portanto, um sistema contábil de relações estabelecidas entre os produtores de um país.

A tabela pode ser explorada a partir de uma visão econômica regional, sendo analisados e projetados os impactos que podem ser notados na estrutura de mudanças. Esse impacto também é notado na dinâmica econômica total do espaço analisado. Pode ser feita uma pesquisa com multiplicadores já definidos, possibilitando a integração dos produtores e a visão das relações entre os agentes (Walter Isard, 1951).

Há uma análise complexa e que relaciona agentes interindustriais. Neste contexto a produção também é relacionada com a demografia e ambientes internos do modelo proposto. A partir de uma busca pelo interesse no sistema socioeconômico há uma menor preocupação com a integração e seus fatores na tabela de insumo-produto (W. Isard \& Anselin, 1982). 
O objetivo da pesquisa é analisar os setores desagregados do agronegócio do estado de Goiás e determinar sua relevância na participação na economia do estado e do país. Para tanto, foi utilizada a Matriz Insumo-Produto Regional do estado em 2016 a partir de quatro agregados de mensuração: insumos utilizados na agricultura e na pecuária; agropecuária; agroindústria; e agroserviços e comércio.

\section{Metodologia}

Foi utilizada a base de dados regional para adequação da metodologia do PiB do Complexo Agroindustrial do estado de Goiás. A busca feita no IBGE buscou compor a coleta de dados para a pesquisa. Os resultados obtidos são a produção das unidades produtivas dos bens e serviços ligadas com a agropecuária, a montante e a jusante, para o ano de 2016 com avaliação de preços de consumidor. A pesquisa tem característica quantitativa, como método de compreensão de fenômenos a partir de coleta, análise e interpretação de dados (Creswell, 2010).

O cálculo do PIB nacional tem um procedimento que é utilizado como modelo para o cálculo do PIB estadual. Sendo assim, a metodologia para o cálculo do PIB do agronegócio é fundamentada nas relações para trás e para frente da agropecuária, antes e depois da porteira, respectivamente. O resultado do PIB do agronegócio é uma adição de quatro aspectos: a) insumos utilizados na agricultura e na pecuária; b) agropecuária; c) agroindústria; e d) agroserviços e comércio.

A seleção dos setores e dos produtos considerados dentro do CAI de GO tem como base as características específicas do estado. Para o cálculo do valor adicionado a preços do consumidor ( $\left.\mathrm{VA}_{\mathrm{PC}}\right)$ é feita a adição do valor adicionado a preços básicos (VA $\left.A_{P B}\right)$ aos impostos indiretos líquidos de subsídios (IIL). A equação (1) é mostrada a seguir:

$$
\mathrm{VA}_{\mathrm{PC}}=\mathrm{VA}_{\mathrm{PB}}+\mathrm{IIL}
$$

O PIB do agregado I (insumos utilizados na agricultura e na pecuária) foi calculado a partir de informações disponíveis sobre as transações da matriz insumo-produto, relacionadas aos valores dos insumos que a agricultura e a pecuária adquiriram. Os valores de tais insumos foram multiplicados pelos coeficientes de valor adicionado do setor $\mathrm{i}\left(\mathrm{CVA}_{\mathrm{i}}\right)$ $(\mathrm{i}=1, \cdots, \mathrm{n})$. Para a obtenção dos CVA's por setor é feita a divisão do (VAPCi) pela produção do mesmo setor. A equação (2) é mostrada a seguir:

$$
\mathrm{CVA}_{\mathrm{i}}=\frac{\mathrm{VA}_{\mathrm{PC}_{\mathrm{i}}}}{\mathrm{X}_{\mathrm{i}}}
$$

A partir do uso desta metodologia é possível eliminar o problema de dupla contagem, que ocorre quando se considera os valores dos insumos e não o valor adicionado efetivamente gerado pela produção, (Furtuoso \& Guilhoto, 2003). Com essas considerações, formulação da agregação dos valores de produção do PIB do agregado I pode ser desenvolvida. A equação (3) é mostrada a seguir:

$$
\mathrm{PIB}_{\text {Ik }}=\sum_{\mathrm{i}=1}^{\mathrm{n}} \mathrm{z}_{\mathrm{ik}} \times \mathrm{CVA}_{\mathrm{i}} \quad \mathrm{k}=1,2
$$

Onde $P I B_{I k}=$ PIB do agregado I (insumos) para agronegócio sem a cadeia de bovinocultura de corte $(\mathrm{k}=1)$ e na cadeia de bovinocultura de corte $(\mathrm{k}=2) ; \mathrm{Z}_{\mathrm{ik}}=$ valor total do insumo para o setor $i$, e $\mathrm{CVA}_{\mathrm{i}}=$ coeficiente de valor adicionado para $\mathrm{o}$ setor $i$.

Para o agregado I total pode-se calcular o PIB total. A equação (4) é mostrada a seguir:

$$
\mathrm{PIB}_{\mathrm{I}}=\mathrm{PIB}_{\mathrm{I}_{1}}+\mathrm{PIB}_{\mathrm{I}_{2}}
$$


Onde: $\mathrm{PIB}_{\mathrm{I}}=\mathrm{PIB}$ do agregado I; $\mathrm{PIB}_{\mathrm{I}_{1}}=$ PIB do agronegócio sem a cadeia de bovinocultura de corte e; $\mathrm{PIB} \mathrm{I}_{2}=\mathrm{PIB}$ da cadeia de bovinocultura de corte.

O PIB do agregado II (agropecuária) foi calculado a partir dos valores adicionados que foram gerados pelos setores. São subtraídos dos valores adicionados os valores dos insumos, eliminando mais uma vez o problema de dupla contagem. A equação (5) é mostrada a seguir:

$$
\mathrm{PIB}_{\text {IIk }}=\mathrm{VA}_{\mathrm{PC}_{\mathrm{k}}}-\sum_{\mathrm{i}=1}^{\mathrm{n}} \mathrm{z}_{\mathrm{ik}} \times \mathrm{CVA}_{\mathrm{i}} \quad \mathrm{k}=1,2
$$

Onde: $\mathrm{PIB}_{\text {IIK }}=$ PIB do agregado II para agronegócio sem a bovinocultura de corte $(\mathrm{k}=1)$ e para a cadeia de bovinocultura de corte $(\mathrm{k}=2)$; e demais variáveis descritas anteriormente.

Para o agregado II total pode-se calcular o PIB total. A equação (6) é mostrada a seguir:

$$
\mathrm{PIB}_{\mathrm{II}}=\mathrm{PIB}_{\mathrm{II}_{1}}+\mathrm{PIB}_{\mathrm{II}_{2}}
$$

Onde: $\mathrm{PIB}_{\mathrm{II}}=\mathrm{PIB}$ do agregado II; $\mathrm{PIB}_{\mathrm{II}_{1}}=\mathrm{PIB}$ do agronegócio sem bovinocultura de corte e; $\mathrm{PIB}_{\mathrm{II}_{2}}=$ PIB da cadeia de bovinocultura de corte.

O PIB do agregado III (agroindústria) foi composto com os dados dos indicadores: a) principais setores que demandam produtos agrícolas, a partir da matriz insumo-produto regional; b) participação dos insumos agrícolas no consumo intermediário dos setores agroindustriais; e c) atividades econômicas que efetuam $1^{\mathrm{a}}, 2^{\mathrm{a}}$ e $3^{\mathrm{a}}$ transformação de matéria-prima agrícola. Com esta definição, foram selecionados os ramos agroindustriais para as atividades do estado: (i) alimentos e bebidas (principalmente frigoríficos); ii) fabricação de produtos de carne iii) ração balanceada para animais. Em sequência, a produção do PIB do agregado III trata de uma soma entre os valores adicionados dos setores agroindustriais subtraídos dos valores adicionais de cada um dos setores que participam como insumos do agregado II. A equação (7) é mostrada a seguir:

$$
\mathrm{PIB}_{\mathrm{IIIk}}=\sum_{\mathrm{q} \in \mathrm{k}}\left(\mathrm{VA}_{\mathrm{PC}_{\mathrm{k}}}-\mathrm{z}_{\mathrm{qk}} \times \mathrm{CVA}_{\mathrm{q}}\right)
$$

Onde: PIB $_{\text {IIIk }}=$ PIB do agregado III para agronegócio sem cadeia de bovinocultura de corte $(\mathrm{k}=1)$ e cadeia de bovinocultura de corte $(\mathrm{k}=2)$ e; $\mathrm{z}_{\mathrm{qk}}=$ valor dos insumos da agroindústria adquirido pela agropecuária.

Para cálculo final do PIB total do agregado III a equação (8) é mostrada a seguir:

$$
\mathrm{PIB}_{\mathrm{III}}=\mathrm{PIB}_{\mathrm{III}_{1}}+\mathrm{PIB}_{\mathrm{II}_{2}}
$$

O PIB do agregado IV (agroserviços e comércio) foi composto com a consideração do valor agregado de setores com relação com o transporte e armazenagem; e comércio e serviços. Do total do valor encontrado é voltado para o agronegócio apenas o montante que corresponde à participação dos produtos da agropecuária e da agroindústria na demanda. O cálculo do valor final de distribuição da agroindústria é mostrado pelas equações (9), (10) e (11) a seguir:

$$
\begin{aligned}
& \mathrm{DFG}-\mathrm{IL}_{\mathrm{DF}}-\mathrm{PI}_{\mathrm{DF}}=\mathrm{DFD} \\
& \mathrm{VAT}_{\mathrm{PC}}+\mathrm{VAC}_{\mathrm{PC}_{\mathrm{C}}}+\mathrm{VAS}_{\mathrm{PC}}=\mathrm{MC} \\
& \mathrm{PIB}_{\mathrm{IV}_{\mathrm{k}}}=\mathrm{MC} * \frac{\mathrm{DF}_{\mathrm{K}}+\sum_{\mathrm{q}=1} \mathrm{DF}_{\mathrm{q}}}{\mathrm{DFD}} \quad \mathrm{k}=1,2
\end{aligned}
$$


Onde: DFG $=$ Demanda Final Global; IILDF $=$ Impostos Indiretos Líquidos pagos pela Demanda Final; PIDF $=$ Produtos Importados pela Demanda Final (do Brasil e Exterior); DFD = Demanda Final Doméstica; VATPC = Valor Adicionado do Setor de Transporte a preços de consumidor; VACPC = Valor Adicionado do Setor de Comércio a preços de consumidor; VASPC $=$ Valor Adicionado do Setor de Serviços a preços de consumidor; MC = Margens de Comercialização; DFk = Demanda Final do agronegócio sem cadeia de bovinocultura de corte $(\mathrm{k}=1)$ e da cadeia de bovinocultura de corte $(\mathrm{k}=2)$; $\mathrm{DFq}=$ Demanda Final dos Setores Agroindustriais; e PIBIVk = PIB do agregado IV para o agronegócio sem a cadeia de bovinocultura de corte $(\mathrm{k}=1)$ e da cadeia de bovinocultura de corte $(\mathrm{k}=2)$.

O total do PIB do agronegócio foi calculado pela soma dos agregados apresentados. A equação (12) é mostrada a seguir:

$$
\mathrm{PIB}_{\text {Agronegócio }_{\mathrm{k}}}=\mathrm{PIB}_{\mathrm{I}_{\mathrm{k}}}+\mathrm{PIB}_{\mathrm{II}_{\mathrm{k}}}+\mathrm{PIB}_{\mathrm{II}_{\mathrm{k}}}+\mathrm{PIB}_{\mathrm{IV}_{\mathrm{k}}}
$$

Onde: $\mathrm{PIB}_{\text {Agronegócio }_{\mathrm{k}}}=$ PIB do agronegócio sem a cadeia de bovinocultura de corte $(\mathrm{k}=1)$ e da cadeia de bovinocultura de corte $(\mathrm{k}=2)$.

O total do PIB do agronegócio, com a soma dos PIB’s, está representado na equação (13) a seguir:

$$
\mathrm{PIB}_{\text {Agronegócio }}=\mathrm{PIB}_{\text {Agronegócio }_{1}}+\mathrm{PIB}_{\text {Agronegócio }_{2}}
$$

O método descrito é representado esquematicamente pela Figura 1 que mostra como ocorre a determinação do PIB do agronegócio. Tal obtenção é feita a partir da soma ponderada do PIB dos agregados apresentados ou também pela soma ponderada do PIB da agricultura e do PIB da pecuária.

Os dados utilizados estão nas bases de contas nacionais (IBGE, 2018b) e regionais (IBGE, 2018c), porém não é divulgado o Produto Interno Bruto da cadeia produtiva. É possível sua determinação a partir do método sugerido com o uso da matriz de insumo-produto regional elaborada com abertura de 30 setores de atividade econômica e de 30 produtos. $\mathrm{O}$ grau de abertura do setor e dos produtos é compatível com a abertura setorial de dos produtos da MIP do Brasil, que é calculada pelo IBGE para 68 setores do país (IBGE, 2018a). 
Figura 1 - Representação da determinação do PIB do agronegócio.
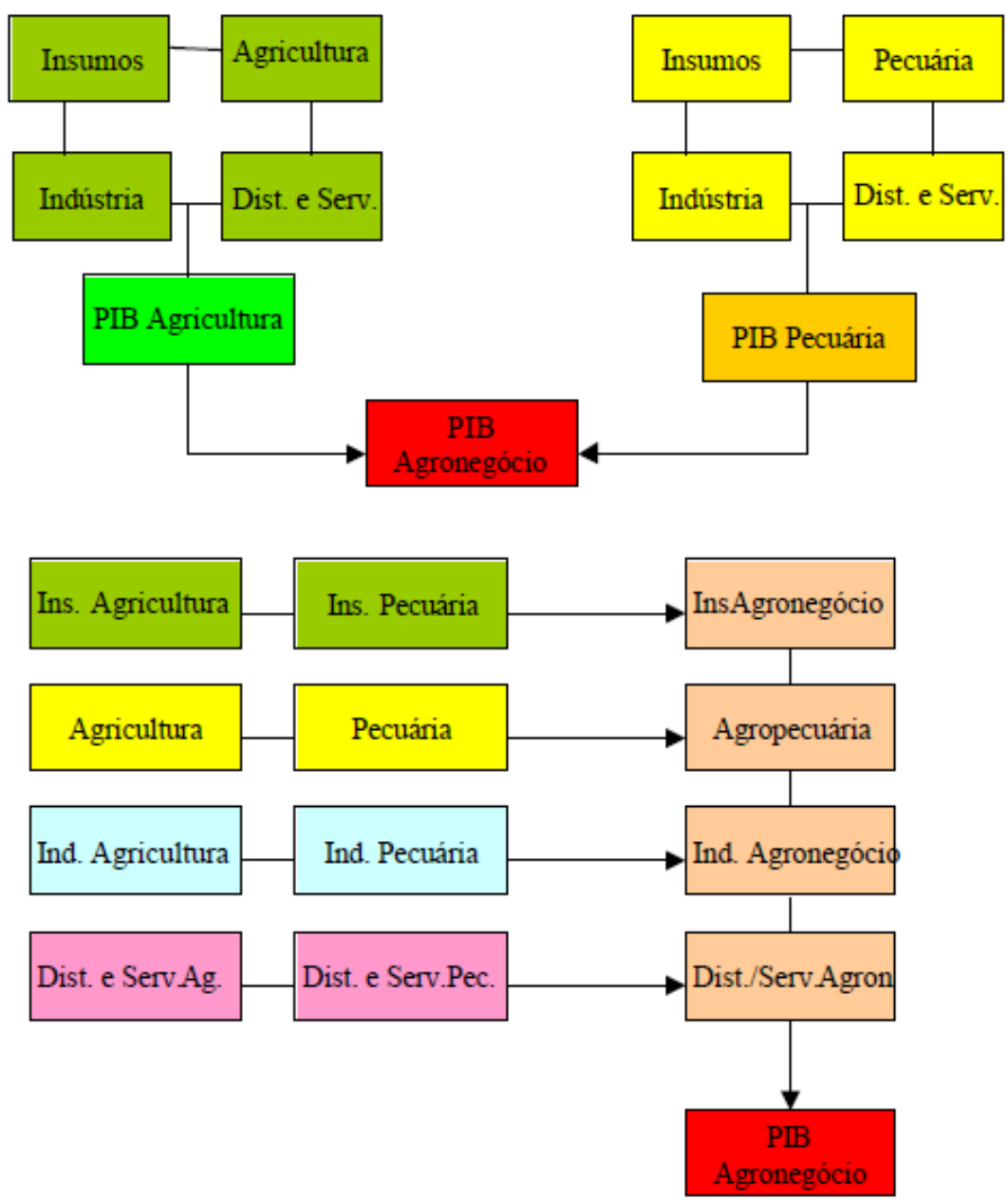

Fonte: Adaptado de Furtuoso e Guilhoto (2003).

Para a obtenção dos dados do comércio com o restante do país e os impostos estaduais foram utilizadas das bases das Secretarias de Estado de Goiás. Para os dados relativos ao comércio internacional e obtenção dos impostos federais foram utilizados dados da Secretaria de Comercio Exterior (SECEX) e da Receita Federal do Brasil (RFB).

\section{Resultados e Discussão}

Um dos setores de destaque no Brasil é o agronegócio, objeto deste estudo, conhecido como o montante de todas as operações de produção e distribuição de insumos agrícolas. Estão incluídos no conceito o armazenamento, processamento, distribuição e também os itens produzidos (Davis \& Goldberg, 1957).

A visão desse conjunto de processos é capaz de levar a interpretações sobre os setores agrícola e industrial brasileiros com a noção macro da sua estrutura. Tal análise leva ao conceito de Complexo Agroindustrial, que pode ser composto por vários sistemas ou cadeias (Machado Filho, 1996), bem como por complexos individuais (Muller, 1989).

A partir de uma perspectiva sistêmica a agropecuária pode ser vista como o sistema econômico de um Complexo Agroindustrial (CAI) (Araujo Neto \& Costa, 2005; Cruz et al., 2009). É possível ser feita a análise por setores a montante e a jusante, sendo considerado este um encadeamento intersetorial subjacente. A Figura 2 mostra tal representação. 
Figura 2 - Representação esquemática da agropecuária à montante e à jusante.

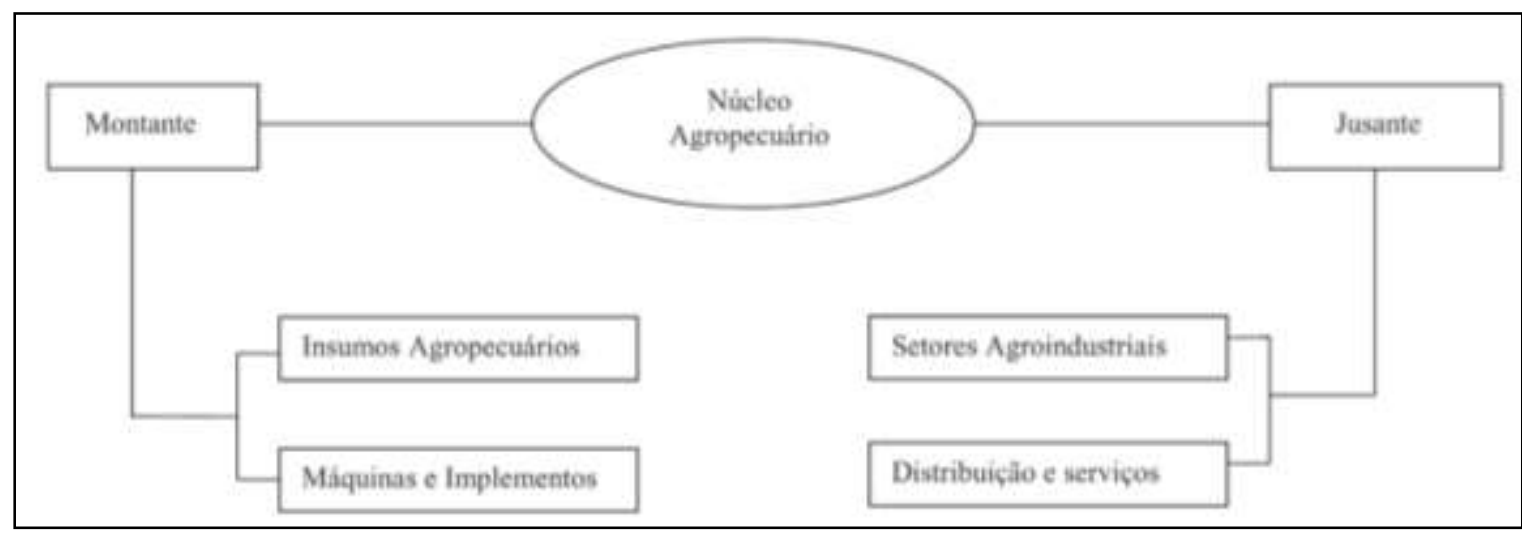

Fonte: Araujo Neto; Costa (2005).

Com essa classificação diversos estudos foram desenvolvidos e aplicados para determinar diagnósticos no Brasil. O CAI se tornou um conceito amplamente analisado e de relevância para análises do agronegócio no país (Correr et al., 2015; Costa et al., 2013; Haas et al., 2010; Palencia, 2016).

$\mathrm{Na}$ análise deve ser considerada a participação dos segmentos para a cadeia produtiva como um todo. Assim como as relações entre o que é adquirido e vendidos entre os diversos setores econômicos. A partir dessa visão, a matriz insumoproduto com seu detalhamento para a análise das cadeias produtivas e as suas atividades é primordial para a construção do diagnóstico relacionado ao agronegócio.

A economia do estado em estudo e os seus setores têm grande proximidade com os setores agropecuários. Isso se dá em participação no PIB, com os insumos a montante e com a indústria de transformação, comércio e serviços. Para calcular os efeitos citados considerou-se os valores adicionados dos grandes setores do estado.

O agronegócio de Goiás, medido a preços básicos, respondeu por 27,60\% do PIB estadual em 2016. A estrutura utilizada para elaborar o PIB do agronegócio a preços do consumidor e a sua participação relativa de cada um dos agregados no PIB estadual e no PIB do agronegócio total são apresentados no Quadro 1.

Quadro 1 - Estrutura do PIB do estado de GO em 2016 a preços do consumidor.

\begin{tabular}{|l|c|c|c|}
\hline \multicolumn{1}{|c|}{ Agregados } & $\begin{array}{c}\text { Valor agregado } \\
\text { a preços ao } \\
\text { consumidor } \\
\text { (em R\$ milhões) }\end{array}$ & $\begin{array}{c}\text { Participação } \\
\text { relativa dos } \\
\text { agregados no } \\
\text { PIB estadual } \\
\mathbf{( \% )}\end{array}$ & $\begin{array}{c}\text { Participação } \\
\text { relativa dos } \\
\text { agregados no PIB } \\
\text { do agronegócio (\%) }\end{array}$ \\
\hline Insumos para agropecuária (Agregado I) & 5.412 .511 & 3,29 & 11,94 \\
\hline Agropecuária (Agregado II) & 16.989 .806 & 10,34 & 37,48 \\
\hline Agroindústria (Agregado III) & 10.354 .594 & 6,30 & 22,84 \\
\hline Distribuição e agroserviços (Agregado IV) & 12.573 .796 & 7,65 & 27,74 \\
\hline Total & 45.330 .707 & 27,60 & 100,00 \\
\hline
\end{tabular}

Fonte: Dados da pesquisa.

O Agregado II, que corresponde à agropecuária, apresenta valores com maior expressividade, se mostrando o principal componente do PIB do agronegócio de Goiás, com 37,48\% de participação. 
Embora grande parte da agropecuária seja de exportações, a parcela de vendas para o interior do país tem uma significativa representação. O Quadro 2 mostra como se comporta a estrutura dos insumos de GO em 2016, a preços do consumidor.

Quadro 2 - Estrutura dos insumos do PIB do agronegócio de GO em 2016 a preços do consumidor.

\begin{tabular}{|l|c|c|c|}
\hline $\begin{array}{c}\text { Insumos } \\
\text { por setor de } \\
\text { atividade }\end{array}$ & $\begin{array}{c}\text { Valor Agregado } \\
\text { a preços de } \\
\text { consumidor } \\
\text { (em R\$ milhões) }\end{array}$ & $\begin{array}{c}\text { Participação } \\
\text { relativa no } \\
\text { agregado I (\%) }\end{array}$ & $\begin{array}{c}\text { Participação } \\
\text { relativa dos } \\
\text { agregados no PIB } \\
\text { do agronegócio } \\
\text { (\%) }\end{array}$ \\
\hline Agricultura & 3.646 .056 & 67,36 & 8,04 \\
Pecuária & 1.766 .455 & 32,64 & 3,90 \\
\hline Total & 5.412 .511 & 100 & 11,94 \\
\hline
\end{tabular}

Fonte: Dados da pesquisa.

A partir dos dados dos Quadros 1 e 2, conclui-se que o Agregado I (insumos do agronegócio a montante) tem participação de 11,94\% do valor total do PIB do agronegócio em GO. Deste percentual 8,04\% corresponde à participação dos insumos da agricultura e 3,90\% corresponde à participação dos insumos da pecuária. Sendo também maiores os valores relativos relacionados à compra dos insumos no estado pela agricultura, $67,36 \%$ contra $32,64 \%$ da pecuária.

O Agregado II está vinculado com os setores urbanos e com o restante da economia. O Quadro 3 apresenta o comportamento da estrutura da agropecuária de GO em 2016, a preços do consumidor.

Quadro 3 - Estrutura da agropecuária do PIB do agronegócio de GO em 2016 a preços do consumidor.

\begin{tabular}{|l|c|c|c|}
\hline $\begin{array}{c}\text { Setores da } \\
\text { agropecuária }\end{array}$ & $\begin{array}{c}\text { Valor Agregado } \\
\text { a preços de } \\
\text { consumidor } \\
\text { (em R\$ milhões) }\end{array}$ & $\begin{array}{c}\text { Participação } \\
\text { relativa no } \\
\text { agregado II (\%) }\end{array}$ & $\begin{array}{c}\text { Participação } \\
\text { relativa dos } \\
\text { agregados no PIB } \\
\text { do agronegócio } \\
\text { (\%) }\end{array}$ \\
\hline Agricultura & 10.420 .367 & $61,33 \%$ & $22,99 \%$ \\
\hline Pecuária & 6.569 .438 & $38,67 \%$ & $14,49 \%$ \\
\hline Total & 16.989 .806 & 100 & $37,48 \%$ \\
\hline
\end{tabular}

Fonte: Dados da pesquisa.

Com a análise dos dados de dados em separado da agricultura e da pecuária foi possível concluir que a agricultura tem participação relativa maior na geração de valor agregado, 61,33\%, em relação à mesma geração da pecuária, 38,67\%. Quando feita a comparação da participação relativa do Agregado II no total do PIB do agronegócio do estado a participação de 37,48\% é dividida em $22,99 \%$ para a agricultura e $14,49 \%$ para a pecuária.

O Quadro 4 apresenta o comportamento da estrutura da agroindústria de GO em 2016, a preços do consumidor. 
Quadro 4 - Estrutura da agroindústria do PIB do agronegócio de GO em 2016 a preços do consumidor.

\begin{tabular}{|l|c|c|c|}
\hline \multicolumn{1}{|c|}{ Setores da agroindústria } & $\begin{array}{c}\text { Valor Agregado } \\
\text { a preços de } \\
\text { consumidor } \\
\text { (em R\$ milhões) }\end{array}$ & $\begin{array}{c}\text { Participação } \\
\text { relativa no } \\
\text { agregado III (\%) }\end{array}$ & $\begin{array}{c}\text { Participação } \\
\text { relativa dos } \\
\text { agregados no PIB } \\
\text { do agronegócio } \\
\text { (\%) }\end{array}$ \\
\hline Carne bovina (reses) & 1.236 .346 & 11,94 & 2,73 \\
\hline $\begin{array}{l}\text { Carne de aves e suínas e outros } \\
\text { pequenos animais }\end{array}$ & 1.498 .419 & 14,47 & 3,31 \\
\hline $\begin{array}{l}\text { Fabricação de óleos vegetais } \\
\text { em bruto, exceto óleo de milho }\end{array}$ & 1.187 .320 & 11,47 & 2,62 \\
\hline Fabricação de laticínios & 1.601 .332 & 15,46 & 3,53 \\
\hline Produção de Açúcar & 1.045 .123 & 10,09 & 2,31 \\
\hline Ração balanceada para animais & 206.293 & 1,99 & 0,46 \\
\hline $\begin{array}{l}\text { Produção de Álcool e } \\
\text { Biocombustíveis }\end{array}$ & 3.579 .761 & 34,57 & 7,90 \\
\hline Total & 10.354 .594 & 100 & $22,84 \%$ \\
\hline
\end{tabular}

Fonte: Dados da pesquisa.

O Agregado III corresponde a $22,84 \%$ do total do PIB do agronegócio de GO, a terceira posição em representatividade tende a ser mantida ou minimizada depois da análise dos dados dos anos posteriores quando houve um recuo de 0,5\% no setor industrial do país e de 0,6\% do estado (SEAPA, 2019). Dos subsetores analisados há maior participação no agregado de produção de álcool e biocombustíveis (34,57\%), fabricação de laticínios $(15,46 \%)$, e carne de aves e suínas e outros pequenos animais $(14,47 \%)$, totalizando $64,50 \%$.

Do Quadro 5 é possível observar que novamente a agricultura tem uma maior participação relativa na geração do valor agregado, com 69,69\% em comparação com $30.31 \%$ da pecuária. Já a participação relativa dos agroserviços no PIB do agronegócio tem seu total de 27,74\% divididos em 19,33\% relacionados à agricultura e 8,41\% relacionados à pecuária do estado. A segunda posição na composição do PIB do agronegócio tendeu a se manter nos próximos anos quando houve um aumento de $0,8 \%$ no setor de serviços do país e de $0,9 \%$ do estado (SEAPA, 2019).

Quadro 5 - Estrutura dos agroserviços do PIB do agronegócio de GO em 2016 a preços do consumidor.

\begin{tabular}{|l|c|c|c|}
\hline \multicolumn{1}{|c|}{ Agroserviços } & $\begin{array}{c}\text { Valor Agregado } \\
\text { a preços de } \\
\text { consumidor } \\
\text { (em R\$ milhões) }\end{array}$ & $\begin{array}{c}\text { Participação } \\
\text { relativa no } \\
\text { agregado IV (\%) }\end{array}$ & $\begin{array}{c}\text { Participação } \\
\text { relativa dos } \\
\text { agregados no PIB } \\
\text { do agronegócio } \\
\text { (\%) }\end{array}$ \\
\hline Agricultura & 8.762 .800 & 69,69 & 19,33 \\
\hline Pecuária & 3.810 .996 & 30,31 & 8,41 \\
\hline Total & 12.573 .796 & 100 & 27,74 \\
\hline
\end{tabular}

Fonte: Dados da pesquisa.

Finalizados os cálculos, a razão entre demanda final e margem de comercialização encontrada na Equação (11) mostra o percentual de participação da demanda final agricultura e da pecuária no comércio de agroserviços de GO. Para a agricultura encontrou-se $29,28 \%$ de participação e para a pecuária $19.31 \%$. 


\section{Conclusão}

O PIB dos agregados do agronegócio analisados corresponde a 27,60\% do total do PIB de Goiás. A relevância do estado para o setor agropecuário foi determinante para a existência do estudo. A associação dos agregados com o PIB do agronegócio pôde ser feita a partir dos resultados encontrados e aplicação da metodologia proposta.

A mensuração de cada agregado mostra a parcela de dependência do PIB do estado de cada um dos setores da economia. A agropecuária é o agregado que tem maior participação no PIB do agronegócio e também no PIB estadual. Em contrapartida o agregado dos insumos para a agropecuária apresentou participação baixa em ambos.

Torna-se possível analisar o peso de cada um dos agregados e seus subsetores para a composição econômica do estado de GO. Tais relações são destaque a montante e a jusante para a estrutura do PIB do agronegócio e suas implicações na tomada de decisão de uma grande variedade de stakeholders envolvidos.

Para futuras pesquisas sugere-se que haja um maior aprofundamento em cada um dos agregados apresentados. Além disso, é importante que seja feita uma comparação com os anos posteriores aos usados nesta pesquisa. Esses processos poderão ser replicados também para outras regiões do país.

\section{Referências}

AGROSTAT. (2019). Estatísticas de Comércio Exterior do Agronegócio Brasileiro. http://indicadores.agricultura.gov.br/index.htm Araujo Neto, D., \& Costa, E. (2005). Dimensionamento do PIB do agronegócio em Pernambuco. Revista de Economia e Sociologia Rural2, 43(4).

CEPEA. (2019). PIB do agronegócio brasileiro. https://www.cepea.esalq.usp.br/br/pib-do-agronegocio-brasileiro.aspx

CNA. (2019). PIB do agronegócio cresce 3,81\% em 2019. https://www.cepea.esalq.usp.br/upload/kceditor/files/Cepea_PIB_CNA_2019.pdf

Correr, G., Santos, M., Zen, S., \& Reydon, B. (2015). O Complexo agroindustrial do leite: estrutura e transformações. 53 Congresso Da Sociedade Brasileira de Economia, Administração e Sociologia Rural. https://doi.org/10.1017/CBO9781107415324.004

Costa, C. C. da, Guilhoto, J. J. M., \& Imori, D. (2013). Importância dos setores agroindustriais na geração de renda e emprego para a economia Brasileira. Revista de Economia e Sociologia Rural, 51(4), 797-814. https://doi.org/10.1590/s0103-20032013000400010

Creswell, J. (2010). Projeto de pesquisa: métodos qualitativo, quantitativo e misto. Artmed.

Cruz, A., Teixeira, E., \& Gomes, M. (2009). O PIB do agronegócio no estado de Minas Gerais. Revista Brasileira de Economia e Sociologia Rural, 47(4).

Davis, J., \& Goldberg, R. (1957). A concept of agribusiness. Harvard University.

EMBRAPA. (2018). VISÃO 2030: O Futuro da Agricultura Brasileira. Embrapa. https://www.embrapa.br/documents/10180/9543845/Visão+2030++o+futuro+da+agricultura+brasileira/2a9a0f27-0ead-991a-8cbf-af8e89d62829?version=1.1

Furtuoso, M. C. O., \& Guilhoto, J. J. M. (2003). Estimativa e mensuração do produto interno bruto do agronegócio da economia brasileira, 1994 a 2000. Revista de Economia e Sociologia Rural, 41(4), 803-827. https://doi.org/10.1590/s0103-20032003000400005

Haas, J. M., Sulzbacher, A. W., Alfredo, J., Bolter, G., \& Neumann, P. S. (2010). O complexo agroindustrial e a agricultura familiar: além das tradicionais fronteiras. Informe GEPEC, 14(2), 60-77.

IBGE. (2018a). Matriz insumo-produto do Brasil. https://www.ibge.gov.br/estatisticas/todos-os-produtos-estatisticas/9085-matriz-de-insumoproduto.html?=\&t=o-que-e

IBGE. (2018b). Sistema de contas nacionais - Brasil. https://www.ibge.gov.br/estatisticas/economicas/contas-nacionais/9052-sistema-de-contas-nacionaisbrasil.html?=\&t=0-que-e

IBGE. (2018c). Sistema de contas regionais - Brasil. https://www.ibge.gov.br/estatisticas/economicas/contas-nacionais/9054-contas-regionais-dobrasil.html?=\&t=o-que-e

IMB. (2016). PIB Goiás 2016. https://www.imb.go.gov.br/files/docs/publicacoes/pib-goias/pibgo2016.pdf

IMB. (2017a). PIB Goiás 2017. https://www.imb.go.gov.br/files/docs/publicacoes/pib-goias/pibgo2017.pdf

IMB. (2017b). Produção agrícola municipal - GO. https://www.imb.go.gov.br/files/docs/releases/pam/pam2017.pdf

Isard, W., \& Anselin, L. (1982). Integration of multiregional models for policy analysis. Environment \& Planning A, 14(3), 359-376. https://doi.org/10.1068/a140359

Isard, Walter. (1951). Interregional and Regional Input-Output Analysis: A Model of a Space-Economy. The Review of Economics and Statistics, 33(4), 318- 
Research, Society and Development, v. 10, n. 5, e9510514668, 2021

(CC BY 4.0) | ISSN 2525-3409 | DOI: http://dx.doi.org/10.33448/rsd-v10i5.14668

328.

Leontief, W. (1936). The Review of Economic Statistics. The Review of Economics and Statistics, 18(3), 105-125. https://doi.org/10.1093/qje/33.1.200

Machado Filho, C. (1996). Agribusiness europeu. Pioneira.

Muller, G. (1989). Complexo agroindustrial e modernização agrária. Hucitec Educ.

Palencia, N. P. (2016). Complexo Agroindustrial d o Leite n o Brasil : Indicadores Socioeconômicos , Adoção d e Tecnologias e Transformações nas Últimas Décadas. Rev. Econ. Do Centro-Oeste, 2(2), 55-72.

SEAPA. (2019). Agro em Dados - GO. http://www.agricultura.go.gov.br/files/AGRO_EM_DADOS_-_DEZEMBRO.pdf 